TITLE:

\title{
A New Amphilochid Species (Crustacea : Amphipoda : Amphilochidae) from a Spiny Lobster
}

\author{
$\operatorname{AUTHOR}(S)$ :
}

Yamato, Shigeyuki

\section{CITATION:}

Yamato, Shigeyuki. A New Amphilochid Species (Crustacea : Amphipoda : Amphilochidae) from a Spiny Lobster. PUBLICATIONS OF THE SETO MARINE BIOLOGICAL LABORATORY 1993, 36(1-2): 99-106

\section{ISSUE DATE:}

1993-03-30

URL:

http://hdl.handle.net/2433/176216

RIGHT: 


\title{
A New Amphilochid Species (Crustacea: Amphipoda: Amphilochidae) from a Spiny Lobster
}

\author{
SHIGEYUKi YaMATo \\ Seto Marine Biological Laboratory, Kyoto University, \\ Shirahama, Wakayama 649-22, Japan
}

With Text-figures $1-3$

\begin{abstract}
A new species of amphilochid amphipod, Gitanopsis iseebi, is described, based on both female and male specimens which were collected from the branchial chamber of a spiny lobster, Panulirus japonicus (von Siebold), at Shirahama, Wakayama, Japan. This new species is sexually dimorphic in the gnathopods 1 and 2; their palmar corners are distinctly produced in the male. This new species is similar to Afrogitanopsis pagui (Myers, 1974), from a pagurid, Dardanus megistos (Herbst) in Kenya, but distinguishable by the antenna 1 and epimeral plates. Taxonomic problems of the family Amphilochidae and the genus Afrogitanopsis are briefly discussed.
\end{abstract}

Key words: Gitanopsis, commensal Amphipoda, subchelate pereopod, spiny lobster, Amphilochidae.

\section{Introduction}

Professor E. Harada gave me an amphipod sample which he collected from the branchial chamber of a spiny lobster, Panulirus japonicus (von Siebold). I was impressed by their subchelate pereopods $3-7$ with which the animal seemed to cling to the host. After dissection, I found that they were very similar to Gitanopsis paguri Myers, 1974, reported to be attached to the body and in the branchial chambers of the pagurid Dardanus megistos (Herbst). Karaman (1980) established a monotypic genus, Afrogitanopsis, for G. paguri, based only on subchelate pereopods 3-7 and progressively longer peduncular articles 1-3 of antenna 1 . In the present paper, I describe the newly collected amphilochid as a new species, and discuss some taxonomic problems in the family Amphilochidae.

Abbreviations used in the figures. A, antenna; E, epimeral plate; G, gnathopod; GL, gill; I., left; LL, lower lip; MD, mandible; MX, maxilla; MXP, maxilliped; OST, oostegite; PA, palp; PL, pleopod; PR, pereopod; $R$, right; $T$, telson; U, uropod; UL, upper lip; $d$, dorsal view; $v$, ventral view.

\section{Description}

\section{Gitanopsis iseebi n. sp.}

(Figs 1-3)

(Japanese name: iseebi-chibiyokoebi, new)

Publ. Seto Mar. Biol. Lab., 36(1/2), 99-106, 1993. (Article 9) 
Material examined. Holotype (SMBL. Type No. 375): ovigerous female, $5.9 \mathrm{~mm}$. Paratypes (SMBL Type No. 376): allotype, male (with penis), $4.9 \mathrm{~mm}$; "m2", male, $4.2 \mathrm{~mm}$; "m3", male, 3.4 $\mathrm{mm}$; "f2", ovigerous female, $5.7 \mathrm{~mm}$; "f $\mathrm{s}$ ", immature female, $3.6 \mathrm{~mm} ; 9$ undissected specimens. All the specimens were collected on 29 April 1992 by Prof. E. Harada, from the branchial chamber of one individual of Panulirus japonicus (von Siebold), caught off Tsubaki ( $33^{\circ} 36^{\prime} \mathrm{N}, 135^{\circ} 24^{\prime} \mathrm{E}$ ) by gill-net and landed at the Tsubaki Fisheries Market of Shirahama, Wakayama, Japan. The type series is deposited in the Seto Marine Biological Laboratory.

\section{Description of holotype}

Body (Fig. 1): Head with distinct rostrum; lateral cephalic lobe tapered distally, obtusely produced; postantennal sinus absent. Eyes large, surrounded by clear ommatidia. Dorsal surface of body smooth, without teeth. Epimeral plates (Fig. 2E) 1--3 with minute setae along ventral margin; plates 1 and 2 slightly produced at posteroventral corner; plate 3 round posteriorly.

Antenna 1 (Fig. 2-A1): Peduncular article 1 exceeding tip of rostrum; article 2 longer than article 3 ; main flagellum with $13+$ articles each of which bears long aesthetascs along ventral margin; accessory flagellum with single minute article. Antenna 2 (Fig. 2-A2) slightly longer than antenna 1; antennal gland cone of peduncular article 2 roundly produced, truncate at opening; article 3 dilated; article 4 with bunches of spines; article 5 longer than 4, with bunches of setae; flagellum with 14 articles each of which bears apical setae.

Upper lip (Fig. 1-UL) incised along ventral margin; unsymmetrically bilobed; right lobe broader than left. Lower lip (Fig. 1-LL): Left half broken in dissection; outer lobe extending laterally; shoulder slightly produced medially; mandible lobe moderately developed; inner lobe small, quadrate.

Mandible (Fig. 1-MD): Incisor 9-dentate; right lacinia mobilis very small, rudimental; left lacinia mobilis 12-dentate; spine row consisting of 15 (right) and 13 (left) pectinate spines; molar process moderately developed, tapered distally; triturating surface of molar distinct, minutely dentate marginally. Palp (Fig. 1-PA) 3-articulate, without setae, pubescent on outer surface of third article and distal half of second article; apex of third article acute.

Maxilla 1 (Fig. 1-MX1): Inner plate round with one seta; outer plate with comb-like pectinate hump at mediodistal corner, 7 robust spines along apical margin, and some setae. Palp biarticulate; first article short, without setae; second article with same structure of apex in right and left palpi, namely, slightly dilated, with three robust spines and one thin spine, and some setae along apical margin.

Maxilla 2 (Fig. 1-MX2): Inner plate larger than outer, with two rows of medial pinnate setae, basal two of which are robust; outer plate with 4 setae; both plates facially and marginally covered with fine setae.

Maxilliped (Fig. 1-MXP): Inner plate with fine setae on medial margin and dorsal surface, two spines on subapical part and with two vestigial processes at apex. Outer plate with one robust spine at apex, row of setae along medial margin, and facial setae on basal part of ventral surface. Palp 4-articulate; palpal articles 1-3 with setae on lateral and medial margins; article 2 short; article 3 pubescent on dor- 


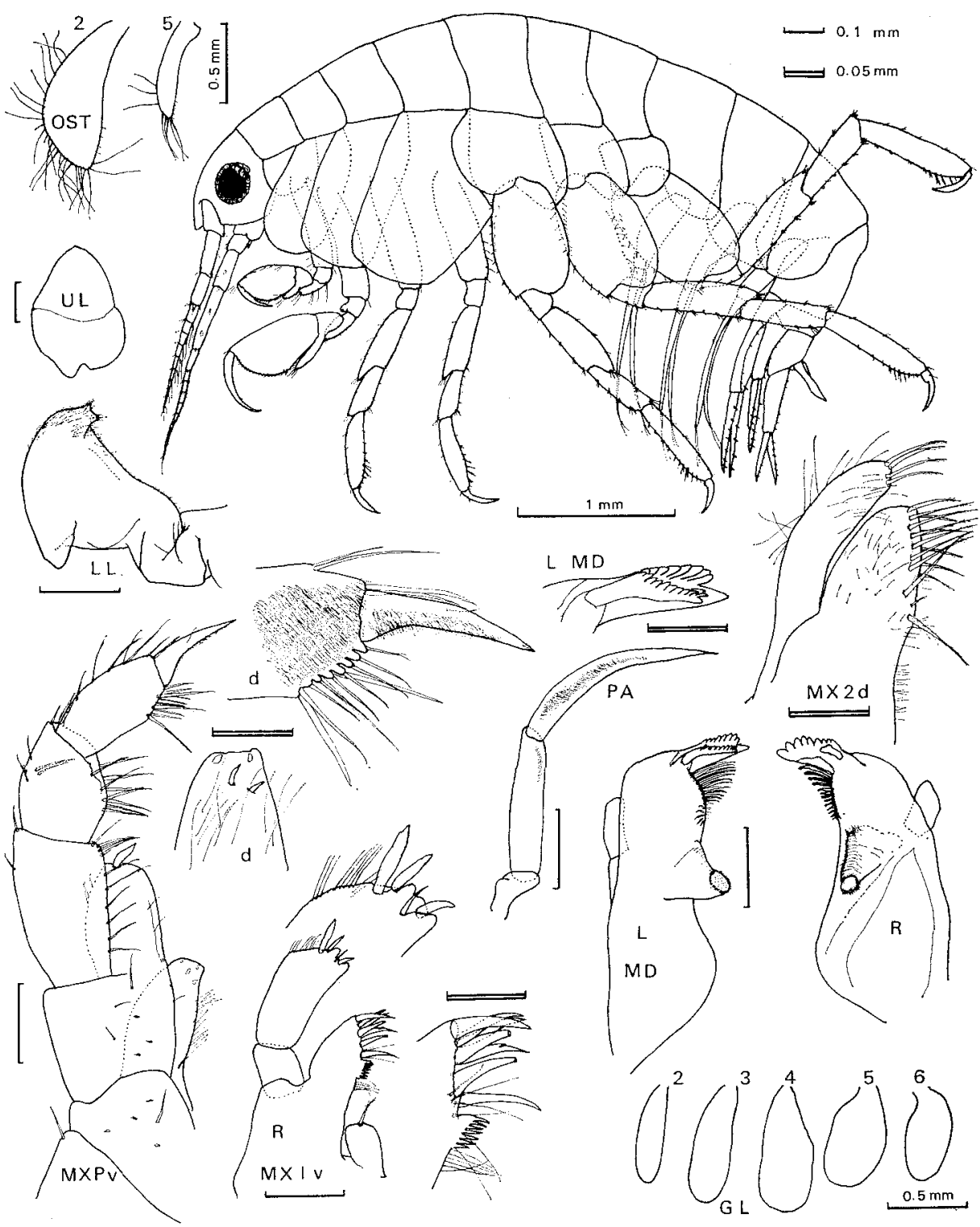

Fig. 1. Gitanopsis iseebi n. sp. Holotype, female, $5.9 \mathrm{~mm}$.

sal surface, with two rows of setae on mediodistal margin and knobbly protrusions on the basal part of each seta; article 4 pubescent on dorsal surface, with acute apex.

Coxa 1 shallow, partially hidden by coxa 2, with some setae on anterior part of ventral margin; coxae 2-4 progressively increasing in length; coxa 4 concave posteroproximally; coxae 5-6 with anterior and posterior lobes; coxa 7 not lobate. Coxal gills (Fig. 1-GL) 2-6 elliptical, simple; gill 4 largest. Oostegites (Fig. 1-OST) 2-4 wide, bearing many long, simple setae along anterior margin and several minute 


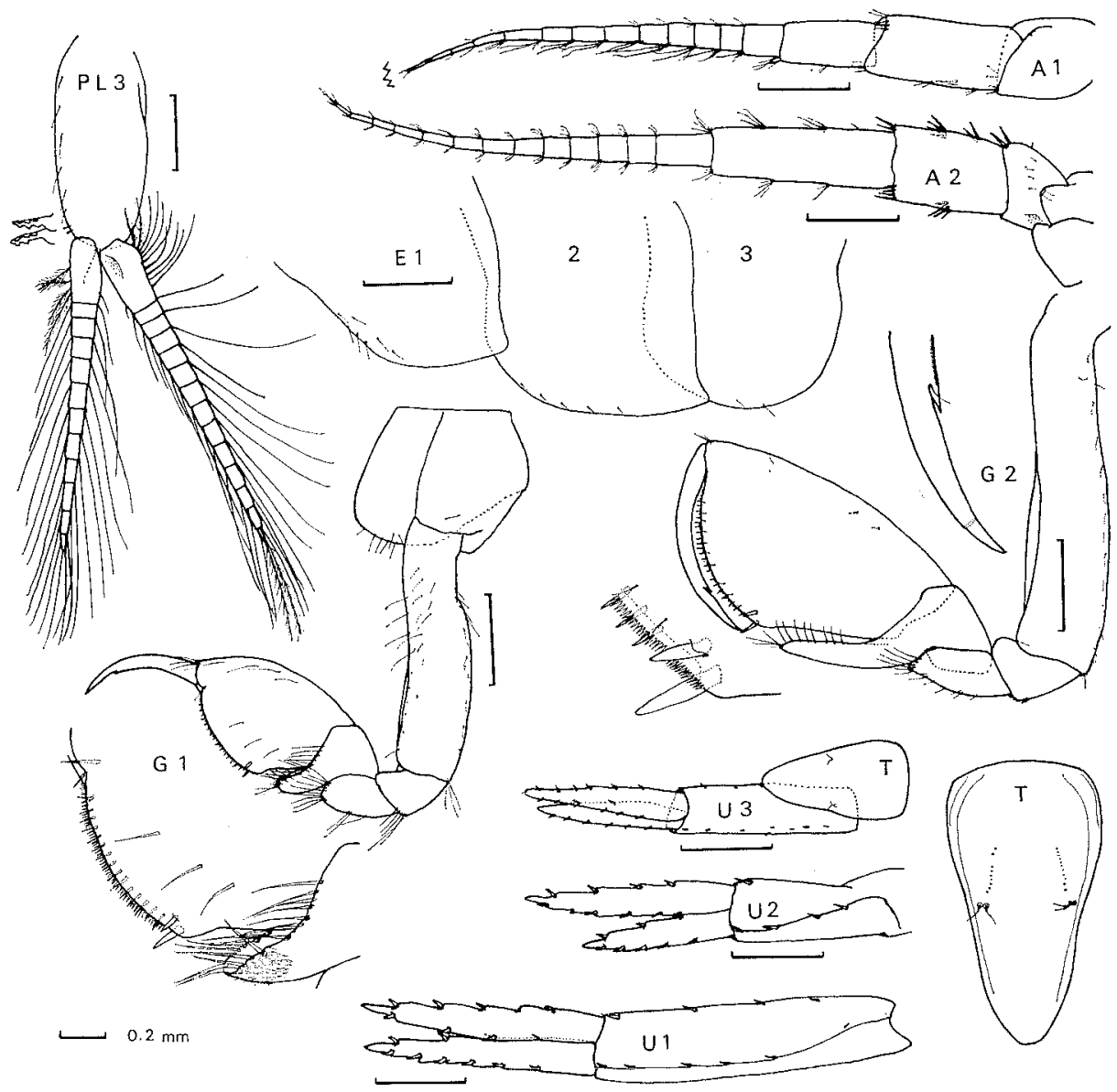

Fig. 2. Gitanopsis iseebi n. sp. Holotype, female, $5.9 \mathrm{~mm}$.

setae along posterior margin; oostegite 5 distinctly smaller than 2-4.

Gnathopod 1 (Fig. 2-G1): Article 2 long, with many marginal setae; article 3 with setae at posterodistal corner; article 4 with setae on posterior margin and posterodistal corner; article 5 with produced lobe which bears marginal setae; article 6 strongly dilated, with short, concave, posterior margin, with some sparse facial setae; palm convex, defined by two distinct spines; palmar margin serrate with distinct minute acute denticles, intermixed with row of bifurcate spinules on outer surface and several minute setae on inner surface; article 7 with minute tooth on medial margin.

Gnathopod 2 (Fig. 2-G2): Article 2 elongate, with row of short setae along posterior margin, concave along anterior margin for reception of articles 5-6; articles 3-4 short; article 5 with elongate posterior lobe bearing setae along its anterior margin, not reaching to palmar corner. Article 6 slightly dilated; posterior margin straight; anterior submargin of outer surface with minute setae; palmar margin distinctly defined by two spines, serrate like that of gnathopod 1, intermixed with row of bifurcate spinules on outer surface and row of minute setae on inner surface. Article 
7 with minute tooth on medial margin.

Pereopods 3 and 4 similar to each other; article 2 long, marginally with short setae; article 3 short; article 4 long, produced anterodistally, marginally with groups of spines; article 5 short with several spines at apex and along posterior margin; article 6 with row of paired spines along posterior margin, forming subchelate structure, together with article 7 ; article 7 with no process on medial margin, with one minute pinnate seta.

Pereopods 5-7 similar to one another; article 2 expanding posteriorly, with spines along anterior margin and one row of minute spines along anterior submargin, and some setae on longitudinal median line of inner surface; article 3 short; article 4 produced posterodistally; articles 4 and 5 marginally with groups of spines; articles $6-7$ as in pereopods 3 and 4.

Pleopods 1-3 (Fig. 2-PL3) similar to each other; peduncle with 2 coupling spines and some marginal setae. Each article of both rami with two apical pinnate setae; basal article of both rami with marginal pinnate setae.

Uropod 1 (Fig. 2-U1) long; peduncle with row of spines along medial and lateral margins; both rami with robust marginal spines inserted in incisions on margins; apex of rami elongate, with no spines. Uropod 2 (Fig. 2-U2) similar to uropod 1; medial margin of peduncle with only one spine; outer ramus distinctly shorter than inner. Uropod 3 similar to uropod 1 but spines on peduncle and rami weaker than those of uropod 1 .

Telson (Fig. 2-T) longer than broad, tapering distally, with one pair of minute pinnate setae on each side.

Description of male

Following differences from female were noticed. Smaller than female. Gnathopod 1 (Fig. 3-G1): Article 2 slightly shorter than that of female; palmar corner of article 6 slightly produced. Gnathopod 2 (Fig. 3-G2): Article 2 shorter than in female; posterior lobe of article 5 short; article 6 ovoid, more bulbous and thicker than in female; palmar corner distinctly produced.

Etymology. The specific name of this new species is the Japanese name for spiny lobsters; noun in apposition.

Remarks. Since the collection of males is very rare in amphilochid amphipods, most species descriptions are based only on female specimens. Even when male specimens were available, the sexual differences were rarely reported. In the present new species, distinct sexual dimorphism is observed in gnathopods 1 and 2; their palmar corners are produced in the male. This kind of shape in the male gnathopods is unique for the Amphilochidae. On the other hand, the female gnathopods of this new species are typical among amphilochids in having a distally dilated article 6 , an evenly convex palm and an elongate article 5 ; the degree of posterodistal elongation of article 5, relative to the palmar corner, has been frequently dis- 


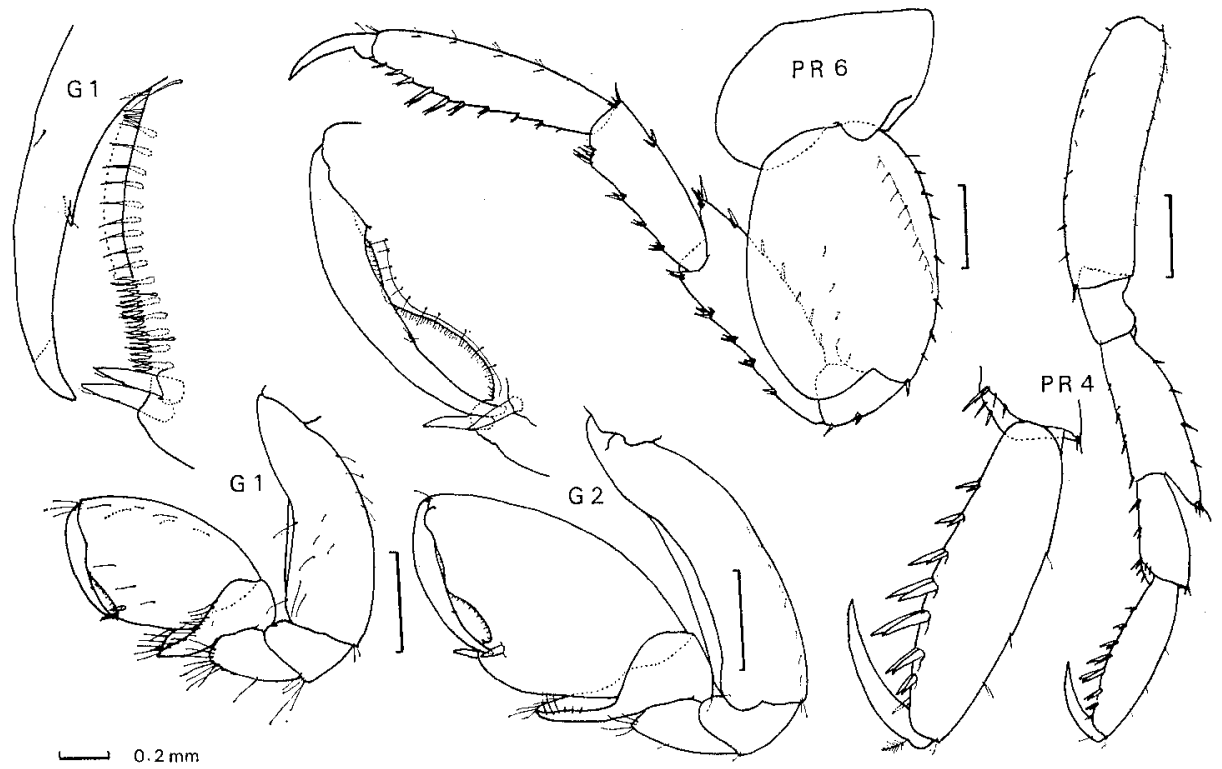

Fig. 3. Gitanopsis iseebi n. sp. Allotype, male, $4.9 \mathrm{~mm}$.

cussed and used in the taxonomy of amphilochids.

This new species is very similar to Gitanopsis paguri Myers, 1974, which was found attached to the body and in the branchial chambers of the pagurid Dardanus megistos (Herbst). Although some characters are not detailed in Myers' description, Gitanopsis iseebi differs from G. paguri in having an antenna 1 with aesthetascs and a peduncular article 2 longer than article 3 , in the produced posteroventral corner of epimeral plates 1 and 2, and in the minutely serrate palmar margin of gnathopod 2 . These two species are readily distinguishable from the other known amphilochid species by the subchelate pereopods 3-7 (see, Hirayama, 1983, for other four species of Gitanopsis from Japanese waters).

Karaman (1980) established the monotypic genus, Afrogitanopsis for Gitanopsis paguri, based only on the two characters, subchelate pereopods 3-7 and progressively longer peduncular articles 1-3 of antenna 1. The new species described herein accords with the former character but not with the latter. In the new species article 2 is the longest of the peduncular articles of antenna 1. Subchelate pereopods are not unusual characters as ordinary amphilochid pereopods could easily change into the palmar configuration by developing a bulge in the distal part of the propodus and acquiring robust spines for reception of the dactylus. Vader (1983) criticizes Karaman's taxonomic change, because "little clarity is to be gained by splitting off single crustacean-associated amphipod species with prehensile pereopods from their congeners". In fact, G. paguri and G. iseebi share many common characteristics in the morphology of mouthparts and gnathopods with other amphilochid species. Since it seems to me that the single character, subchelate pereopods $3-7$, is not in itself sufficient to support the establishment of separate genus Afrogitanopsis, I decline to 
adopt this genus.

As many authors repeatedly pointed out in the family Amphilochidae (e.g. Schellenberg, 1926; Hurley, 1955; Karaman, 1980), the generic distinction between Amphilochus and Gitanopsis, which differ only in the mandible molar, is ambiguous. When Sars (1895) established the genus Gitanopsis, the diagnoses of the two genera were explicit; the mandible molar of the type species and other two species of Gitanopsis is distinctly larger than that of Amphilochus. Since that time, intermediate forms of the mandible molar have been found and the definitions of the two genera have been confused. Some authors referred to the size of the molar, others to its triturating surface or armature. More recetly Barnard \& Karaman (1991) defined the characteristics of the mandible molar for the two genera as follows: for Amphilochus, mandible molar small, columnar, conical or weakly bulbous, poorly or not triturative; for Gitanopsis, mandible molar large, cushion shaped, triturative. They also added various deviations from the diagnosis as "variables" for each genus. However, among the species listed by them, several species could be placed in either genus and their allocation appears to be inconsistent; for example, Gitanopsis baciroa Barnard, 1979 and Amphilochus kailua Barnard, 1970 could have been placed in the genera Amphilochus and Gitanopsis respectively. The mandible molar of the present new species is the case in point. Thus, the distinction between Gitanopsis and Amphilochus needs to be studied and examined further and I place the present new species in the genus Gitanopsis only in relation to Gitanopsis paguri.

\section{Acknowledgments}

I am indebted to Professor E. Harada of the Seto Marine Biological Laboratory for providing the material for this study and for reading the manuscript and making a number of helpful comments. I would like to thank Dr. G.C. Kearn of the University of East Anglia for reading the manuscript and improving the English of the text.

\section{References}

Barnard, J.L. 1962. Benthic marine Amphipoda of southern California: Families Amphilochidae, Leucothoidae, Stenothoidae, Argissidae, Hyalidae. Pac. Nat., 3: 116-163.

-2 1970. Sublittoral Gammaridea (Amphipoda) of the Hawaiian Islands. Smiths. Contr. Zool., 34: 1-286.

- 1979. Littoral gammaridean Amphipoda from the Gulf of California and the Galapagos Islands. Smiths. Contr. Zool., 271 : i-vi $+1-149$.

Barnard, J.L. \& Karaman, G.S. 1991. The families and genera of marine gammaridean Amphipoda (Except marine gammaroids). Part 1 and 2. Rec. Austr. Mus., Suppl. 13: 1-866.

Hirayama, A. 1983. Taxonomic studies on the shallow water gammaridean Amphipoda of West Kyushu, Japan. I. Acanthonotozomatidae, Ampeliscidae, Ampithoidae, Amphilochidae, Anamixidae, Argissidae, Atylidae and Colomastigidae. Publ. Seto Mar. Biol. Lab., 28: 75-150

Hurley, D.E. 1955. Studies on the New Zealand amphipodan fauna no. 12. The marine families Stegocephalidae and Amphilochidae. Trans. Roy. Soc. N.Z., 83: 195-221.

Karaman, G.S. 1980. Revision of the genus Gitanopsis Sars 1895 with description of new genera Ajrogitanopsis and Rostrogitanopsis n. gen. (fam. Amphilochidae). (Contribution to the knowledge of the Amphipoda 104). Poljoprivreda i Sumarstvo, 26: 43-69. 
Myers, A.A. 1974. A new species of commensal amphipod from east Africa. Crustaceana, 26: 3336.

Sars, G.O. 1895. Amphipoda. An account of the Crustacea of Norway with short descriptions and figures of all the species, 1 : $\mathrm{i}$-viii $+1-711,248$ pls.

Schellenberg, A. 1926. Gammariden der Deutschen Südpolar-Expedition 1901-1903. Deutsche Südpolar Expedition, 18 (Zoologie 10) : 235-414.

Vader, W. 1983. Prehensile pereopods in gammaridean Amphipoda. Sarsia, 68: 139-148. 